\title{
BMJ Open Clinical and economic impact of intensive care unit-acquired bloodstream infections in Taiwan: a nationwide population-based retrospective cohort study
}

\author{
Yung-Chih Wang, ${ }^{1}$ Shu-Man Shih, ${ }^{2}$ Yung-Tai Chen, ${ }^{3,4,5}$ Chao Agnes Hsiung, ${ }^{2}$ \\ Shu-Chen Kuo (iD ${ }^{6}$
}

To cite: Wang Y-C, Shih S$\mathrm{M}$, Chen Y-T, et al. Clinical and economic impact of intensive care unit-acquired bloodstream infections in Taiwan: a nationwide population-based retrospective cohort study. BMJ Open 2020;10:e037484. doi:10.1136/ bmjopen-2020-037484

- Prepublication history and additional material for this paper are available online. To view these files, please visit the journal online (http://dx.doi. org/10.1136/bmjopen-2020037484).

Received 04 February 2020 Revised 30 0ctober 2020 Accepted 06 November 2020

Check for updates

(C) Author(s) (or their employer(s)) 2020. Re-use permitted under CC BY-NC. No commercial re-use. See rights and permissions. Published by BMJ.

For numbered affiliations see end of article.

\section{Correspondence to}

Dr Shu-Chen Kuo; sckuo@nhri.edu.tw and Dr Shu-Chen Kuo; sckuo@nhri.edu.tw

\section{ABSTRACT}

Objectives To estimate the clinical and economic impact of intensive care unit-acquired bloodstream infections in Taiwan.

Design Retrospective cohort study.

Setting Nationwide Taiwanese population in the National Health Insurance Research Database and the Taiwan Nosocomial Infections Surveillance (2007-2015) dataset. Participants The first episodes of intensive care unitacquired bloodstream infections in patients $\geq 20$ years of age in the datasets. Propensity score-matching (1:2) of demographic data, comorbidities and disease severity was performed to select a comparison cohort from a pool of intensive care unit patients without intensive care unitacquired infections from the same datasets.

Primary and secondary outcome measures The mortality rate, length of hospitalisation and healthcare cost.

Results After matching, the in-hospital mortality of 14234 patients with intensive care unit-acquired bloodstream infections was $44.23 \%$, compared with $33.48 \%$ for 28468 intensive care unit patients without infections. The 14day mortality rate was also higher in the bloodstream infections cohort (4323, $30.37 \%$ vs 6766 deaths, $23.77 \%$, respectively; $p<0.001)$. Furthermore, the patients with intensive care unit-acquired bloodstream infections had a prolonged length of hospitalisation after their index date (18 days (IQR 7-39) vs 10 days (IQR 4-21), respectively; $\mathrm{p}<0.001$ ) and a higher healthcare cost (US $\$ 16038$ (IQR 9667-25946) vs US\$10372 (IQR 6289-16932), respectively; $p<0.001)$. The excessive hospital stay and healthcare cost per case were 12.69 days and US\$7669, respectively. Similar results were observed in subgroup analyses of various WHO's priority pathogens and Candida spp.

Conclusions Intensive care unit-acquired bloodstream infections in critically ill patients were associated with increased mortality, longer hospital stays and higher healthcare costs.

\section{INTRODUCTION}

Critically ill patients in intensive care units (ICUs) are vulnerable to various infections,

\section{Strengths and limitations of this study}

- A large number of patients obtained from Nationwide Taiwanese population from two datasets in Taiwan were included

- Propensity score-matching was performed to select a comparison cohort.

- The mortality rate, length of hospitalisation and healthcare cost were analysed.

- Subgroup analyses of several drug-resistant pathogens were conducted.

The retrospective design may include some unmeasurable bias.

and these can lead to increased morbidity, mortality and healthcare costs. Bloodstream infections (BSIs) are one of the most common infections acquired by ICU patients. It was reported that BSIs affected approximately $7 \%$ of patients admitted to ICUs. ${ }^{1}$ Previous studies have shown that ICU-acquired BSIs resulted in attributable mortality of $24.8 \%,{ }^{2}$ extended hospital stays by 13.5 days $^{3}$ and the cost of treatment was approximately US\$12321 per case. Moreover, despite advances in medical care and the development of new therapies, the outcome of BSIs in critically ill patients is adversely affected by a greater number of vulnerable hosts and the emergence of drugresistant pathogens.

Discrepancies regarding the impact of pathogens on mortality have been reported. However, worse clinical outcome and higher economic burden have been reported for patients with BSI caused by resistant pathogens. ${ }^{4}$ For example, BSIs involving third-generation cephalosporin-resistant Enterobacteriaceae have been shown to significantly increase mortality risk compared with BSIs involving susceptible strains. ${ }^{4}$ 
Moreover, candidemia has been associated with a fourfold increase in mortality, while Staphylococcus aureus BSIs doubled the risk of mortality. ${ }^{1}$ Meanwhile, the clinical impact of enterococci remains a controversial topic. ${ }^{5-7}$ Therefore, it is important not only to describe the clinical and economic impact of infections, but also to decipher the impact of individual pathogens. Due to the limited number of cases and the complex clinical characteristics of critically ill patients, previous studies have reported either clinical or economic outcomes, have focused on several species of pathogens or have assessed only a limited number of pathogens. In the present study, a health insurance database and a nationwide surveillance system for healthcare-associated infections were used to estimate the clinical and economic consequences of ICUacquired BSIs caused by different pathogens in a large number of patients in Taiwan. In addition, the impact of individual pathogens, especially antibiotic-resistant bacteria on the WHO priority list, ${ }^{8}$ were investigated.

\section{METHODS}

\section{Data sources}

Two datasets, the National Health Insurance Research Database (NHIRD) and the Taiwan Nosocomial Infection Surveillance (TNIS) dataset, were used in this study. Demographic data, diagnoses (according to the International Classification of Diseases, 9th Revision, Clinical Modification (ICD-9-CM)), procedures and medications for patients enrolled in Taiwan's national insurance system have been collected in the NHIRD since $1995 .{ }^{9}$ In 2007, the TNIS was launched by the Taiwan Centers for Disease Control to evaluate the epidemiologic trend of healthcare-associated infections in the ICUs in Taiwan. The latter is a web-based surveillance system which collects clinical information of patients with healthcareassociated infections from the ICUs of participating hospitals. This information includes demographic data, infection foci, causative pathogens and antimicrobial susceptibility results. Participation in TNIS is essential for hospital accreditation in Taiwan.

Both datasets were deposited in a database maintained by the Health and Welfare Data Science Center, Ministry of Health and Welfare. Individual personal identification numbers were encrypted so that data from the NHIRD and TNIS datasets could be interlinked.

\section{Study population, data collection and propensity-score matching}

This retrospective cohort study enrolled adult patients who underwent ICU hospitalisation between 2007 and 2015 in Taiwan. From the entries in the TNIS database, we identified all of the patients whose first episode of an ICU-acquired BSI occurred during the study period. Coagulase-negative staphylococci are often identified in the ICUs but a certain proportion is associated with contamination; therefore, these cases were not included in our analysis. We included species that constituted $>1 \%$ of known bloodstream pathogens (online supplemental table 1), which constituted $79.4 \%$ of all ICU-acquired BSI episodes. The index date for each case was defined as the date on which a positive blood culture result was obtained. The encrypted personal identification numbers of included patients were interlinked with NHIRD to retrieve their demographic data, comorbidities, procedures and medications.

For comparison, we identified ICU patients who did not have ICU-acquired infections registered in TNIS database. In addition, patients with a discharge diagnosis of sepsis (ICD-9-CM: 038.X, 995.91), severe sepsis (ICD-9-CM: 995.92) or septic shock (ICD-9-CM: 785.52) in the comparison cohort, but not in the BSI group, were also excluded. The pool of comparison patients was created for the selection of those with the same admission date as any patient with ICU-acquired BSI. Because the comparison patients did not have index date of acquisition of infection, they were assigned 'pseudo-index dates' during hospitalisation, which was selected from the index date of patients with the same day of hospitalisation in the BSI group. Baseline variables and those associated with ICU-acquired BSIs were first selected. Propensity scores were then calculated for the likelihood of ICU-acquired BSIs by multivariate logistic regression analysis. Variables were removed from the multivariable model in a stepwise fashion. We used 1:2 greedy matching ${ }^{10}$ within a calliper width equal to 0.1 of the SD of the logit of the propensity score (online supplemental table 2). Patient data from January 2005 were used to ensure that individuals were followed for at least 2 years prior to their selection for this study in order to confirm comorbidities ${ }^{11}$ and for matching purposes. The determination of comorbidities and organ dysfunction by ICD-9-CM codes were in accordance with the previous studies. ${ }^{11-13}$ The variables with missing values included monthly income and urbanisation level. Missing values were treated as a separate category by itself. The low rate of missing data (table 1) may not have a great impact on our study.

\section{Patient and public involvement}

Patients and the public were not directly involved in the planning of this study.

\section{Outcome measurements}

Clinical outcomes included in-hospital, 14-day and 28-day mortality rate after the index date/pseudo-index date. Economic outcomes included hospitalisation length after the index date/pseudo-index date and cost of overall hospitalisation. Hospitalisation length was defined as the duration of hospital stay after the index date/pseudoindex date. The overall cost of hospitalisation was calculated. The costs were standardised and presented in values from 2017.

\section{Subgroup analysis}

To evaluate the clinical and economic impact of ICUacquired BSIs caused by different pathogens, we 
Table 1 Characteristics of the intensive care unit patients with bloodstream infections and the matched comparison cohort

\section{Characteristics}

No of patients

Year of index date

\begin{tabular}{|c|c|c|c|}
\hline 2007 & 1244 (8.74\%) & 3474 (12.2\%) & 0.113 \\
\hline 2008 & $1608(11.3 \%)$ & 3101 (10.89\%) & 0.013 \\
\hline 2009 & $1714(12.04 \%)$ & 2923 (10.27\%) & 0.056 \\
\hline 2010 & 1745 (12.26\%) & 3119 (10.96\%) & 0.041 \\
\hline 2011 & 1947 (13.68\%) & 3107 (10.91\%) & 0.084 \\
\hline 2012 & 1727 (12.13\%) & 3119 (10.96\%) & 0.037 \\
\hline 2013 & $1496(10.51 \%)$ & 2985 (10.49\%) & 0.001 \\
\hline 2014 & 1371 (9.63\%) & $3226(11.33 \%)$ & 0.056 \\
\hline 2015 & $1382(9.71 \%)$ & 3414 (11.99\%) & 0.073 \\
\hline \multicolumn{4}{|l|}{ Season of in-date } \\
\hline Mar-May & 3564 (25.04\%) & 7207 (25.32\%) & 0.006 \\
\hline Jun-Aug & 3577 (25.13\%) & 7224 (25.38\%) & 0.006 \\
\hline Sep-Nov & $3519(24.72 \%)$ & 6964 (24.46\%) & 0.006 \\
\hline Dec-Feb & 3574 (25.11\%) & 7073 (24.85\%) & 0.006 \\
\hline Males & $8971(63.03 \%)$ & $17861(62.74 \%)$ & 0.006 \\
\hline Age, years, mean (SD) & $65.12(21.62)$ & $65.08(20.60)$ & 0.002 \\
\hline $\begin{array}{l}\text { Length of stay before index date/pseudo-index date, } \\
\text { days, mean (SD) }\end{array}$ & $15.69(12.14)$ & $15.29(11.96)$ & 0.033 \\
\hline \multicolumn{4}{|l|}{ Monthly income, US\$ } \\
\hline Dependent & $2416(16.97 \%)$ & $4813(16.91 \%)$ & 0.002 \\
\hline$<657.33$ & $4740(33.3 \%)$ & $9575(33.63 \%)$ & 0.007 \\
\hline $657.33-1504.60$ & $6324(44.43 \%)$ & $12563(44.13 \%)$ & 0.006 \\
\hline$>1504.60$ & $740(5.2 \%)$ & $1484(5.21 \%)$ & 0.001 \\
\hline Unknown & $14(0.1 \%)$ & $33(0.12 \%)$ & 0.005 \\
\hline \multicolumn{4}{|l|}{ Urbanisation level } \\
\hline 1 (urban) & $3639(25.57 \%)$ & $7293(25.62 \%)$ & 0.001 \\
\hline 2 & $3968(27.88 \%)$ & $7920(27.82 \%)$ & 0.001 \\
\hline 3 & $2227(15.65 \%)$ & $4432(15.57 \%)$ & 0.002 \\
\hline 4 (rural) & $4389(30.83 \%)$ & $8802(30.92 \%)$ & 0.002 \\
\hline Unknown & $11(0.08 \%)$ & $21(0.07 \%)$ & 0.001 \\
\hline \multicolumn{4}{|l|}{ Hospital level } \\
\hline Medical centre & $7168(50.36 \%)$ & $14393(50.56 \%)$ & 0.004 \\
\hline Regional hospital & $6125(43.03 \%)$ & $12242(43 \%)$ & 0.001 \\
\hline Local hospital & $940(6.6 \%)$ & $1833(6.44 \%)$ & 0.007 \\
\hline Charlson Comorbidity Index Score, mean (SD) & $3.085(2.80)$ & $3.105(2.95)$ & 0.007 \\
\hline 0 & $2950(20.73 \%)$ & $6411(22.52 \%)$ & 0.044 \\
\hline 1 & $1930(13.56 \%)$ & $3928(13.8 \%)$ & 0.007 \\
\hline 2 & $2283(16.04 \%)$ & $4251(14.93 \%)$ & 0.031 \\
\hline$\geq 3$ & $7071(49.68 \%)$ & $13878(48.75 \%)$ & 0.019 \\
\hline \multicolumn{4}{|l|}{ Comorbidities } \\
\hline Diabetes mellitus & $4840(34 \%)$ & $9642(33.87 \%)$ & 0.003 \\
\hline Cerebrovascular disease & $3552(24.95 \%)$ & $7048(24.76 \%)$ & 0.005 \\
\hline
\end{tabular}

Continued

Standardised difference
Patients with BSI

14234

$1244(8.74 \%)$

$1714(12.04 \%)$

(12.26\%)

1727 (12.13\%)

3564 (25.04\%)

3574 (25.11\%)

(21.62)

$2416(16.97 \%)$

$40(5.2 \%)$

3639 (25.57\%)

$389(30.83 \%)$

$7168(50.36 \%)$

$125(43.03 \%)$

$3.085(2.80)$

1930 (13.56\%)

$2283(16.04 \%)$
Comparison cohort 28468

$7073(24.85 \%)$ 
Table 1 Continued

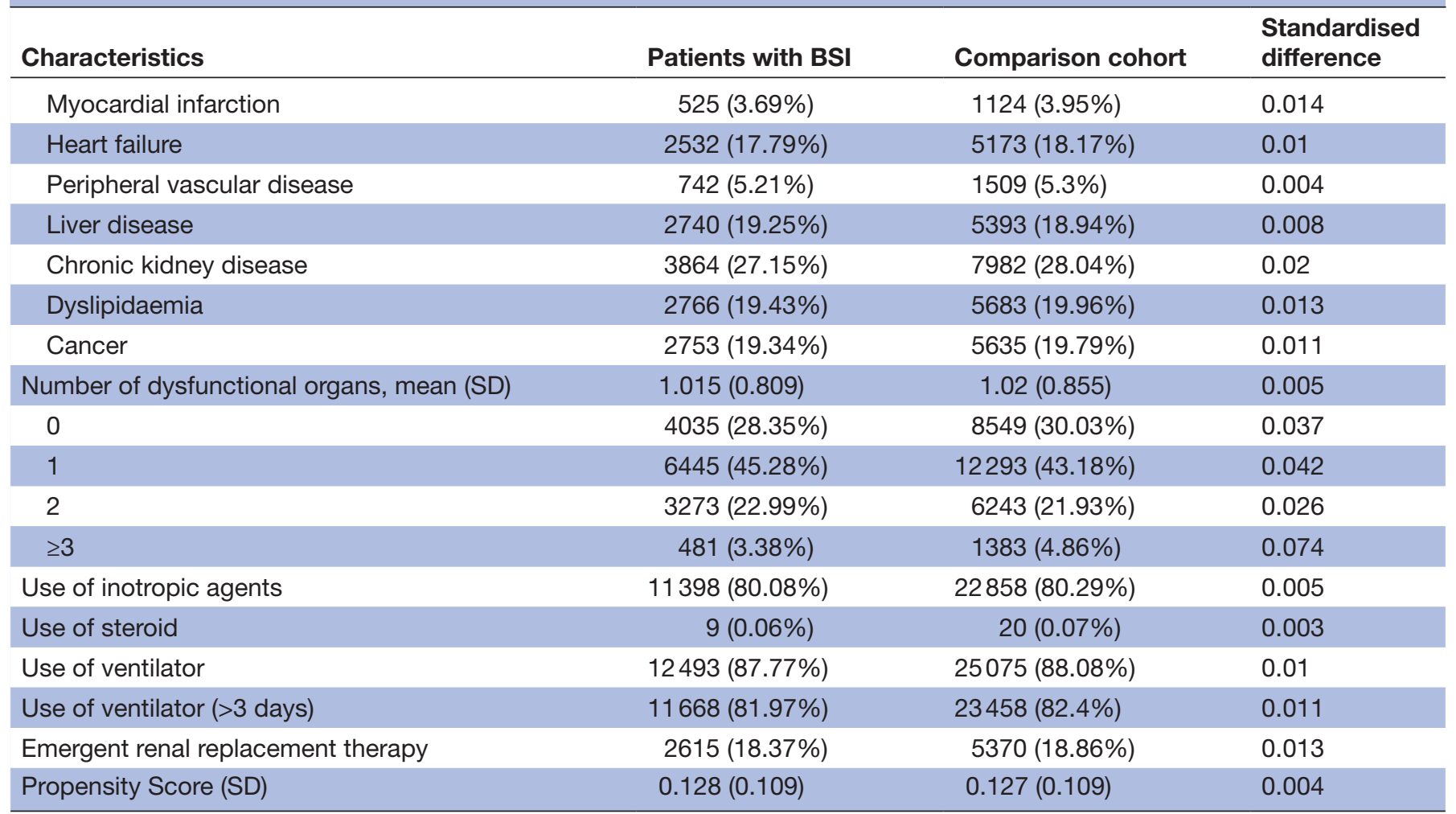

BSI, bloodstream infection.

performed analyses on patients infected with single pathogen. For example, the impact of WHO priority bacteria and Candida were examined separately, as was the impact of drug resistance in these bacteria. We included patients whose first episode of an ICU-acquired BSI were caused by bacteria on the WHO priority list or Candida. Therefore, the clinical and economic outcomes of patients with Acinetobacter baumannii, Pseudomonas aeruginosa, common Enterobacteriaceae (Escherichia coli, Klebsiella pneumoniae, Enterobacter species, and Serratia marcescens), S. aureus, Enterococcus species, Candida albicans and non-albicans Candida (Candida tropicalis, Candida parapsilosis and Candida glabrata) were determined.

The definition of multiple drug resistance (MDR) of WHO priority bacteria according to the European Centre for Disease Prevention and Control was modified ${ }^{14}$ (online supplemental table 3 ). In this study, non-susceptibility to at least one agent in at least three antimicrobial categories in Gram-negative bacteria was defined as MDR. Oxacillinnon-susceptible and vancomycin-non-susceptible $S$. aureus and vancomycin-non-susceptible Enterococcus species were considered MDR Gram-positive bacteria.

\section{Sensitivity analysis}

To avoid competing risk between mortality and length of hospitalisation/healthcare cost, we included patients who survived to discharge. For these patients, the length of hospitalisation after the index date/pseudo-index date and hospitalisation costs were determined.

\section{Statistical analysis}

Descriptive statistics were used to examine baseline demographic and clinical characteristics of the ICU patients included in this study. To account for potential confounding biases among the study cohort, propensity score matching analysis was performed. Propensity scores were calculated with multivariate logistic regression. Standardised differences between the two groups with differences less than 0.1 were confirmed in order to assess baseline characteristics. The Mann-Whitney $\mathrm{U}$ test was used to evaluate economic outcomes and the $\chi^{2}$ test was used to evaluate mortality rate. Conditional logistic regression was used to calculate ORs to evaluate risk of mortality in patients with BSI and the comparison cohort, while a generalised linear model was used to calculate $\beta$ values to estimate excess costs and length of hospitalisation. Variables with a $\mathrm{p}$ value $<0.05$ were eligible for inclusion in the model. P values less than 0.05 were considered statistically significant. All analyses were performed by using SAS statistical software (V.9.4, SAS Institute).

\section{RESULTS}

Among 38659 episodes of ICU-acquired BSIs registered in TNIS during the 9-year study period, 28495 patients were identified to have their first episode of a BSI. The NHIRD included 1638796 patients who underwent ICU hospitalisation (figure 1). After excluding patients whose 
Patients with ICUacquired BSI

38,659 episodes of BSI in TNIS

during 2007-2015

8,495 patients with the first episode of BSI in TNIS during 2007-2015
Patients without

ICU-acquired infections
$1,638,796$ patients in

NHIRD with ICUs

admission during 20072015

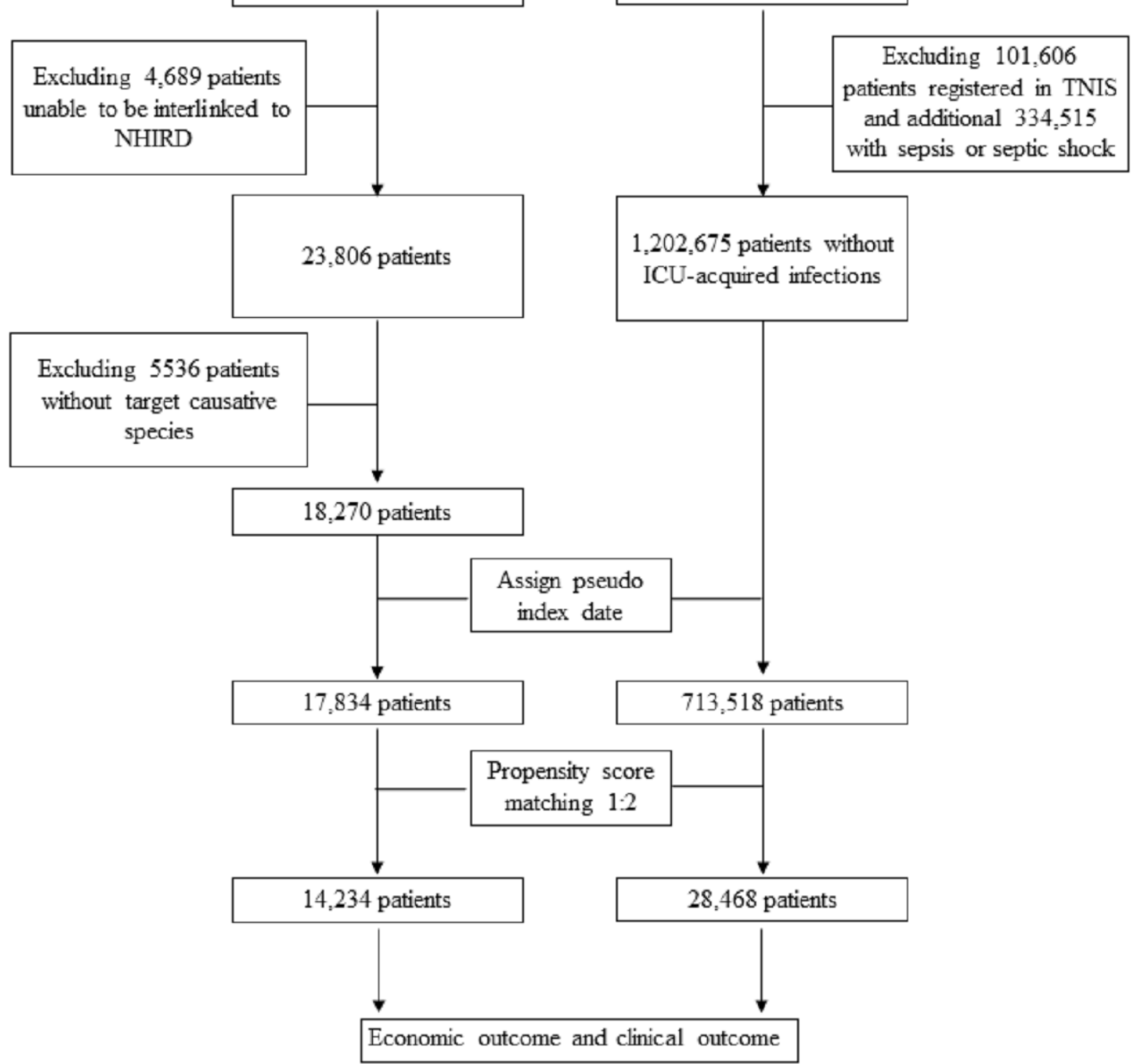

Figure 1 Flow diagram of the study design. BSI, bloodstream infection; ICU intensive care unit; NHIRD, National Health Insurance Research Database; TNIS, Taiwan Nosocomial Infections Surveillance. 
Table 2 Clinical and economic outcomes among patients with bloodstream infections and the matched comparison cohort

\begin{tabular}{|c|c|c|c|c|c|c|}
\hline \multirow[b]{2}{*}{ Outcomes } & \multicolumn{3}{|l|}{ Full cohort } & \multicolumn{3}{|l|}{ Matched cohort } \\
\hline & ICU patients with BSI & Comparison cohort & $P$ value & ICU patients with BSI & Comparison cohort & $P$ value \\
\hline No of patients & 17834 & 713518 & & 14234 & 28468 & \\
\hline In-hospital mortality, n (\%) & 8639 (48.44) & $65282(9.15)$ & $<0.0001$ & $6295(44.23)$ & $9532(33.48)$ & $<0.0001$ \\
\hline 14-day mortality, n (\%) & $5693(31.92)$ & $54998(7.71)$ & $<0.0001$ & $4323(30.37)$ & $6766(23.77)$ & $<0.0001$ \\
\hline 28-day mortality, n (\%) & 7469 (41.88) & $73552(10.31)$ & $<0.0001$ & $5619(39.48)$ & $9189(32.28)$ & $<0.0001$ \\
\hline $\begin{array}{l}\text { Length of hospitalisation after the } \\
\text { index date/pseudo-index date, days, } \\
\text { median (IQR) }\end{array}$ & $18(6-40)$ & $6(3-13)$ & $<0.0001$ & $18(7-39)$ & $10(4-21)$ & $<0.0001$ \\
\hline $\begin{array}{l}\text { Cost of hospitalisation (US\$), } \\
\text { median (IQR) }\end{array}$ & $\begin{array}{l}18457 \\
(10938-30778)\end{array}$ & $\begin{array}{l}4971 \\
(2770-8598)\end{array}$ & $<0.0001$ & $\begin{array}{l}16038 \\
(9667-25946)\end{array}$ & $\begin{array}{l}10372 \\
(6289-16932)\end{array}$ & $<0.0001$ \\
\hline
\end{tabular}

*The costs are standardised and presented as the values in 2017

$\mathrm{BSI}$, bloodstream infection; ; ICU, intensive care unit.

data could not be interlinked with NHIRD or who did not have target pathogens, 14234 patients with ICU-acquired BSIs were successfully matched to 28468 ICU patients without ICU-acquired infections (1:2). The demographic and clinical characteristics of the patients with BSI and comparison cohort are presented in table 1 . The groups had standardised differences that were $<10 \%$ for all of the continuous and dichotomous categorical variables which were examined.

Table 2 lists the clinical and economic outcomes of the ICU patients with BSIs and the comparison cohort. The ICU patients with BSIs suffered a higher in-hospital mortality rate $(44.23 \%$ vs $33.48 \%$, respectively; $\mathrm{p}<0.001)$, a higher 14 -day mortality rate $(30.37 \%$ vs $23.77 \%$, respectively; $\mathrm{p}<0.001)$ and a higher 28-day mortality $(39.48 \%$ vs $32.28 \%$, respectively; $\mathrm{p}<0.001)$. Logistic regression analyses showed that the OR of in-hospital mortality for the ICU patients with BSIs was 1.67 (95\% CI, 1.59-1.75; $\mathrm{p}<0.001)$, and it was $1.42(95 \%$ CI, 1.35-1.49; $\mathrm{p}<0.001)$ for 14-day mortality and 1.41 (95\% CI, 1.34-1.47; $\mathrm{p}<0.001)$ for 28-day mortality. These significant associations were also observed in the subgroup analyses performed (table 3).

The ICU patients with BSIs had a longer length of hospitalisation after the index date (18 days vs 10 days, respectively; $\mathrm{p}<0.001)$. Moreover, on average, their hospital stay was extended by 12.69 days (95\% CI, 11.9213.47; $\mathrm{p}<0.001)$. The subgroup analyses performed (table 4) showed that all of the causative pathogens shared a similar trend. Compared with the patients without ICU-acquired infections, the duration of hospitalisation after the index date for those with BSIs caused by MDR bacteria, WHO priority bacteria or Candida spp. was longer. In addition, hospitalisation costs of the ICU patients with BSIs were higher (16038 vs 10 372, respectively; $\mathrm{p}<0.001)$ (table 2), with the excess cost being US\$7669 per patient (95\% CI, 7380-7958; p<0.001).

\begin{tabular}{|c|c|c|c|}
\hline \multirow{2}{*}{$\begin{array}{l}\text { Pathogen groups } \\
\text { (no of patients) }\end{array}$} & \multicolumn{3}{|l|}{ Odds ratio $(95 \% \mathrm{Cl})$} \\
\hline & In-hospital mortality & 14-day mortality & 28-day mortality \\
\hline MDR Gram-positive bacteria (1429) & $1.84(1.59-2.12)$ & $1.52(1.31-1.76)$ & $1.5(1.3-1.72)$ \\
\hline Acinetobacter baumannii (1761) & $1.67(1.47-1.91)$ & $1.45(1.26-1.66)$ & $1.45(1.27-1.66)$ \\
\hline Enterobacteriaceae* (3548) & $1.59(1.45-1.75)$ & $1.28(1.16-1.41)$ & $1.31(1.19-1.43)$ \\
\hline Staphylococcus aureus (1721) & $1.63(1.42-1.87)$ & $1.24(1.07-1.44)$ & $1.31(1.15-1.51)$ \\
\hline Enterococcus species† (1277) & $1.87(1.6-2.18)$ & $1.69(1.44-1.99)$ & $1.6(1.37-1.85)$ \\
\hline Candida albicans (951) & $2.04(1.71-2.43)$ & $1.61(1.35-1.91)$ & $1.68(1.42-1.98)$ \\
\hline
\end{tabular}

${ }^{*}$ Enterobacteriaceae included Escherichia coli, Klebsiella pneumoniae, Enterobacter cloacae, Enterobacter aerogenesa and Serratia marcescens.

†Enterococcus species included Enterococcus faecium, Enterococcus faecalis and other Enterococcus species.

$\ddagger$ Non-albicans Candida included Candida tropicalis, Candida parapsilosis and Candida glabrata.

$\S$ Only patients with bloodstream infections involving a single pathogen were included in this analysis.

MDR, multiple drug resistance. 
Table 4 Economic outcomes for the various pathogen groups

\begin{tabular}{llr}
\hline & Excess costs or length of hospitalisation (95\% Cl) \\
\cline { 2 - 3 } Pathogen groups & Length of hospitalisation after the index date (days) & Cost of hospitalisation (US\$) \\
\hline MDR Gram-negative bacteria & $10.41(8.55-12.27)$ & $7563(6725-8401)$ \\
\hline MDR Gram-positive bacteria & $13.82(11.38-16.27)$ & $6342(5500-7184)$ \\
Acinetobacter baumannii & $9.4(7.65-11.14)$ & $6727(5823-7632)$ \\
\hline Pseudomonas aeruginosa & $10.01(7.83-12.19)$ & $6761(5609-7913)$ \\
Enterobacteriacea* & $15.05(13.33-16.76)$ & $7444(6881-8007)$ \\
Staphylococcus aureus & $14.72(12.63-16.81)$ & $5211(4528-5894)$ \\
\hline Enterococcus species $†$ & $10.66(7.85-13.48)$ & $7219(6305-8132)$ \\
\hline Candida albicans & $11.37(8.82-13.92)$ & $8688(7512-9864)$ \\
\hline Non-albicans Candidał & $15.13(11.77-18.49)$ & $11476(10025-12927)$ \\
\hline
\end{tabular}

*Enterobacteriaceae included Escherichia coli, Klebsiella pneumoniae, Enterobacter cloacae, Enterobacter aerogenes and Serratia marcescens.

$\dagger$ Enterococcus species included Enterococcus faecium, Enterococcus faecalis and other Enterococcus species. $\ddagger$ Non-albicans Candida included Candida tropicalis, Candida parapsilosis and Candida glabrata. §Only patients with bloodstream infections involving a single pathogen were included in this analysis. MDR, multiple drug resistance.

Table 4 presents the higher costs associated with each of the various causative pathogens.

For the ICU patients with BSIs who survived to discharge, their length of hospitalisation and healthcare costs were increased by 19.59 days and US $\$ 8871$, respectively (online supplemental table 4) compared with the survivors without ICU-acquired infections.

\section{DISCUSSION}

This study demonstrated that ICU patients with BSIs in Taiwan had significantly worse clinical outcomes and higher economic burden than ICU patients without ICU-acquired infections from the same population. For example, the patients with BSI exhibited 1.67-fold, 1.42fold and 1.41-fold increases in in-hospital, 14-day and 28-day mortality rates, respectively. Per case, the patients with BSI had an excess hospital stay of 12.69 days and cost of US $\$ 7669$. Furthermore, a similar clinical and economic impact was observed among all of the causative pathogens examined.

BSIs have been associated with higher mortality and morbidity, contingent on the causative pathogen involved. ${ }^{13} 15-18$ For example, worse clinical outcomes have been reported for patients with BSIs caused by $A$. baumannii, ${ }^{1819}$ P. aeruginosa, ${ }^{17}{ }^{18}$ S. aureus, ${ }^{141718}$ Enterobacteriaceae ${ }^{418}$ and Candida spp. ${ }^{1820}$ In contrast, controversial results have been obtained regarding the mortality of patients affected by enterococcal bacteremia. While some authors have argued that Enterococcus spp. represents a low virulence pathogen ${ }^{1}$ and is not associated with increased mortality unless in the presence of endocarditis, ${ }^{21}$ other authors have reported contrasting results. ${ }^{561820}$ In the present study, significantly higher mortality was observed for patients with enterococcal bacteremia, and this may be due to vulnerability of the hosts examined, increased resistance and a larger study population.

The high healthcare burden of BSIs reported in previous literature ${ }^{31522}$ and in the present study underscores the importance of preventing ICU-acquired BSIs by infection control measurements. Furthermore, the results of these studies help to assess cost effectiveness of infection control measurements in the process of policy-making. For example, patients with ICU-acquired BSIs during the 9-year period cost Taiwan an estimated US $\$ 297$ million and 492129 days (online supplemental table 5). A policy that reduced the rate of infection by $10 \%{ }^{23}$ would translate into a savings of US $\$ 30$ million and 49213 patient-days saved.

Drug resistance has been found to be correlated with higher medical costs due to the need for second-line antimicrobials for treatment, as well as additional diagnostic and treatment tools. ${ }^{24}{ }^{25}$ In the present study, the costs for MDR bacteria included extra US\$84 million and 140043 days over 9 years (online supplemental table 5). However, cost differences between susceptible and resistant strains were not determined in the present study. Drugsusceptible strains were not included as controls due to differences in testing methods, drugs and breakpoints for these strains which could lead to mis-assignments of drugresistant pathogens as susceptible pathogens.

Candidemia poses a great threat to ICU patients due to its excessive medical burdens, ${ }^{18} 2022$ and C. albicans is the most common pathogen. However, in some countries, the prevalence of non-albicans Candida exceeds that of C. albicans. ${ }^{26}$ For those infected with non-albicans Candida, higher rates of mortality, ${ }^{26}$ longer hospitalisation stays and increased hospital costs have been described $^{27-29}$; although other studies have reported contradicting findings. ${ }^{30} 31$ These discrepancies may 
be due to host factors and differences in the virulence and resistance patterns ${ }^{26}$ of non-albicans Candida. In the present study, the crude 14-day and in-hospital mortality rates of 951 patients infected with C. albicans were $37.96 \%$ and $55.94 \%$, respectively. In comparison, among 703 patients infected with non-albicans Candida, these rates were $34.99 \%$ and $53.06 \%$, respectively. While the hospital costs and length of stay were higher in the non-albicans Candida group compared with the C. albicans group, the 95\% CI overlapped for the two groups (table 4). These data suggested that the clinical and economic outcomes of these two groups did not greatly differ. However, the present study was not designed to specifically compare the outcomes of those infected with C. albicans versus non-albicans Candida. Therefore, additional studies with a larger number of patients, adjustment for host factors and consideration of antifungal drugs, incubation time and treatment duration are needed to clarify the impact of each Candida species.

The large number of patients examined in this study and the use of propensity score matching represent two major strengths of the present study. These aspects also allowed the impact of each pathogen group to be discerned. However, there were also several limitations associated with the present study which merit discussion. First, the exact cost after the index date could not be retrieved from the NHIRD. Therefore, the high total cost shown in this study may be due to costs incurred prior to the onset of a BSI. It is possible that matching of the duration before the index date and comorbidity may have reduced overestimations of healthcare costs due to timedependent bias. ${ }^{32}$ Second, confounding factors associated with clinical impact, such as Acute Physiology and Chronic Health Evaluation II (APACHE II) or Pitt Bacteremia scores, were not included in this study. Instead, other clinical risk factors (Charlson Comorbidity Index Score, number of organ failures, use of inotropic agents and receipt of invasive procedures) were incorporated in our model. Third, our study is inherently limited by its retrospective design, which includes a dependence on the accuracy of the ICD codes used and unmeasurable bias. ${ }^{33}$ Fourth, the prolonged hospitalisation may have been due to a change in patient management in response to a BSI, rather than increased morbidity due to a BSI. ${ }^{17}$ Fifth, the number of participating hospitals varied during study period and therefore was considered in propensity score matching. Finally, the collection of personal identification numbers is not mandatory in TNIS, which resulted in failure of interlink. However, their impact on the outcome was unknown. In addition, the administrative data are inherently subjected to coding errors and changes in coding practices. ${ }^{34}$

\section{CONCLUSIONS}

ICU-acquired BSIs have a negative clinical and economic impact on affected patients regardless of the causative pathogens involved. Awareness of these negative affects is important for promoting infection control measurements and for policy-making.

\section{Author affiliations}

${ }^{1}$ Division of Infectious Diseases and Tropical Medicine, Department of Internal Medicine, National Defense Medical Center, Taipei, Taiwan

${ }^{2}$ Institute of Population Health Sciences, National Health Research Institutes, Zhunan, Miaoli County, Taiwan

${ }^{3}$ Department of Medicine, Taipei City Hospital Heping Fuyou Branch, Taipei, Taiwan ${ }^{4}$ University of Taipei, Taipei, Taiwan

${ }^{5}$ Divisions of Nephrology, Taipei Veterans General Hospital, Taipei, Taiwan

${ }^{6}$ National Institute of Infectious Diseases and Vaccinology, National Health Research Institutes, Zhunan, Miaoli County, Taiwan

Contributors $\mathrm{CAH}$ and S-CK are involved in conceptualisation and validation. Y-TC, CAH and S-CK contributed to data curation, resources and methodology. S-MS and Y-TC involved in formal analysis, supervision and software. Y-CW and S-CK involved in funding acquisition and investigation. Y-CW, CAH and S-CK contributed to project administration and writing, review and editing. Y-CW and S-MS involved in visualisation. Y-CW, S-MS and S-CK involved in writing the original draft. All authors approved the final version of the manuscript.

Funding This work was supported by a grant from the National Health Research Institutes (Grant no. 108-0324-01-19-06) and Tri-Service General Hospital (TSGHC107-099 and TSGH-E-109237).

Disclaimer The sponsors had no role in the study design; collection, analysis or interpretation of data; writing of the report or the decision to submit the article for publication.

Competing interests None declared.

Patient consent for publication Not required.

Ethics approval The institutional review board of the National Health Research Institutes approved this study (EC1051207-R4).

Provenance and peer review Not commissioned; externally peer reviewed.

Data availability statement Data may be obtained from a third party and are not publicly available. The data that support the findings of this study are available from Ministry of Health and Welfare, Taiwan but restrictions apply to the availability of these data, which were used under license for the current study, and so are not publicly available. Data are however available from the authors upon reasonable request and with permission of Ministry of Health and Welfare, Taiwan.

Supplemental material This content has been supplied by the author(s). It has not been vetted by BMJ Publishing Group Limited (BMJ) and may not have been peer-reviewed. Any opinions or recommendations discussed are solely those of the author(s) and are not endorsed by BMJ. BMJ disclaims all liability and responsibility arising from any reliance placed on the content. Where the content includes any translated material, BMJ does not warrant the accuracy and reliability of the translations (including but not limited to local regulations, clinical guidelines, terminology, drug names and drug dosages), and is not responsible for any error and/or omissions arising from translation and adaptation or otherwise.

Open access This is an open access article distributed in accordance with the Creative Commons Attribution Non Commercial (CC BY-NC 4.0) license, which permits others to distribute, remix, adapt, build upon this work non-commercially, and license their derivative works on different terms, provided the original work is properly cited, appropriate credit is given, any changes made indicated, and the use is non-commercial. See: http://creativecommons.org/licenses/by-nc/4.0/.

ORCID iD

Shu-Chen Kuo http://orcid.org/0000-0002-6940-6450

\section{REFERENCES}

1 Prowle JR, Echeverri JE, Ligabo EV, et al. Acquired bloodstream infection in the intensive care unit: incidence and attributable mortality. Crit Care 2011;15:R100.

2 Garrouste-Orgeas M, Timsit JF, Tafflet M, et al. Excess risk of death from intensive care unit-acquired nosocomial bloodstream infections: a reappraisal. Clin Infect Dis 2006;42:1118-26.

3 Laupland KB, Lee H, Gregson DB, et al. Cost of intensive care unitacquired bloodstream infections. J Hosp Infect 2006;63:124-32. 
4 Stewardson AJ, Allignol A, Beyersmann J, et al. The health and economic burden of bloodstream infections caused by antimicrobial-susceptible and non-susceptible Enterobacteriaceae and Staphylococcus aureus in European hospitals, 2010 and 2011: a multicentre retrospective cohort study. Euro Surveill 2016;21:pii=30319.

5 Landry SL, Kaiser DL, Wenzel RP. Hospital stay and mortality attributed to nosocomial enterococcal bacteremia: a controlled study. Am J Infect Control 1989;17:323-9.

6 Ong DSY, Bonten MJM, Safdari K, et al. Epidemiology, management, and risk-adjusted mortality of icu-acquired enterococcal bacteremia. Clin Infect Dis 2015;61:1413-20.

7 Kramer TS, Remschmidt C, Werner S, et al. The importance of adjusting for enterococcus species when assessing the burden of vancomycin resistance: a cohort study including over 1000 cases of enterococcal bloodstream infections. Antimicrob Resist Infect Control 2018;7:133.

8 Tacconelli E, Carrara E, Savoldi A, et al. Discovery, research, and development of new antibiotics: the who priority list of antibiotic-resistant bacteria and tuberculosis. Lancet Infect Dis 2018;18:318-27

9 Wu T-Y, Majeed A, Kuo KN. An overview of the healthcare system in Taiwan. London J Prim Care 2010;3:115-9.

10 Tu JV, Bowen J, Chiu M, et al. Effectiveness and safety of drugeluting stents in Ontario. N Engl J Med 2007;357:1393-402.

11 Deyo RA, Cherkin DC, Ciol MA. Adapting a clinical comorbidity index for use with ICD-9-CM administrative databases. J Clin Epidemiol 1992;45:613-9.

12 Quan H, Sundararajan V, Halfon P, et al. Coding algorithms for defining comorbidities in ICD-9-CM and ICD-10 administrative data. Med Care 2005;43:1130-9.

13 Shen H-N, Lu C-L, Li C-Y. Effect of diabetes on severity and hospital mortality in patients with acute pancreatitis: a national populationbased study. Diabetes Care 2012;35:1061-6.

14 Magiorakos A-P, Srinivasan A, Carey RB, et al. Multidrug-Resistant, extensively drug-resistant and pandrug-resistant bacteria: an international expert proposal for interim standard definitions for acquired resistance. Clin Microbiol Infect 2012;18:268-81.

15 Pittet D, Tarara D, Wenzel RP. Nosocomial bloodstream infection in critically ill patients. excess length of stay, extra costs, and attributable mortality. JAMA 1994;271:1598-601.

16 Laupland KB, Zygun DA, Davies HD, et al. Population-Based assessment of intensive care unit-acquired bloodstream infections in adults: incidence, risk factors, and associated mortality rate. Crit Care Med 2002;30:2462-7.

17 Barnett AG, Page K, Campbell M, et al. The increased risks of death and extra lengths of hospital and ICU stay from hospitalacquired bloodstream infections: a case-control study. BMJ Open 2013;3:e003587.

18 Marra AR, Camargo LFA, Pignatari ACC, et al. Nosocomial bloodstream infections in Brazilian hospitals: analysis of 2,563 cases from a prospective nationwide surveillance study. J Clin Microbiol 2011;49:1866-71.

19 Lemos EV, de la Hoz FP, Einarson TR, et al. Carbapenem resistance and mortality in patients with Acinetobacter baumannii infection: systematic review and meta-analysis. Clin Microbiol Infect 2014;20:416-23.

20 Schwab F, Geffers C, Behnke M, et al. ICU mortality following ICUacquired primary bloodstream infections according to the type of pathogen: a prospective cohort study in 937 Germany ICUs (20062015). PLoS One 2018;13:e0194210.

21 Caballero-Granado FJ, Becerril B, Cuberos L, et al. Attributable mortality rate and duration of hospital stay associated with enterococcal bacteremia. Clin Infect Dis 2001;32:587-94.

22 Blot SI, Depuydt P, Annemans L, et al. Clinical and economic outcomes in critically ill patients with nosocomial catheter-related bloodstream infections. Clin Infect Dis 2005;41:1591-8.

23 Tseng S-H, Lee C-M, Lin T-Y, et al. Combating antimicrobial resistance: antimicrobial stewardship program in Taiwan. J Microbiol Immunol Infect 2012;45:79-89.

24 Howard D, Cordell R, McGowan JE, et al. Measuring the economic costs of antimicrobial resistance in hospital settings: summary of the centers for disease control and Prevention-Emory workshop. Clin Infect Dis 2001;33:1573-8.

25 Mauldin PD, Salgado CD, Hansen IS, et al. Attributable hospital cost and length of stay associated with health care-associated infections caused by antibiotic-resistant gram-negative bacteria. Antimicrob Agents Chemother 2010;54:109-15.

26 Horn DL, Neofytos D, Anaissie EJ, et al. Epidemiology and outcomes of candidemia in 2019 patients: data from the prospective antifungal therapy alliance registry. Clin Infect Dis 2009;48:1695-703.

27 Dimopoulos G, Ntziora F, Rachiotis G, et al. Candida albicans versus non-albicans intensive care unit-acquired bloodstream infections: differences in risk factors and outcome. Anesth Analg 2008;106:523-9.

28 Moran C, Grussemeyer CA, Spalding JR, et al. Comparison of costs, length of stay, and mortality associated with Candida glabrata and Candida albicans bloodstream infections. Am J Infect Control 2010;38:78-80.

29 Gong X, Luan T, Wu X, et al. Invasive candidiasis in intensive care units in China: risk factors and prognoses of Candida albicans and non-albicans Candida infections. Am J Infect Control 2016;44:e59-63.

30 Pfaller M, Neofytos D, Diekema D, et al. Epidemiology and outcomes of candidemia in 3648 patients: data from the prospective antifungal therapy (path Alliance $\AA$ ) registry, 2004-2008. Diagn Microbiol Infect Dis 2012;74:323-31.

31 Barchiesi F, Orsetti E, Gesuita R, et al. Epidemiology, clinical characteristics, and outcome of candidemia in a tertiary referral center in Italy from 2010 to 2014. Infection 2016;44:205-13.

32 Nelson RE, Samore MH, Jones M, et al. Reducing timedependent bias in estimates of the attributable cost of health care-associated methicillin-resistant Staphylococcus aureus infections: a comparison of three estimation strategies. Med Care 2015;53:827-34.

33 Kuo S-C, Shih S-M, Hsieh L-Y, et al. Antibiotic restriction policy paradoxically increased private drug consumptions outside Taiwan's National health insurance. J Antimicrob Chemother 2017;72:1544-5.

34 Sarrazin MSV, Rosenthal GE. Finding pure and simple truths with administrative data. JAMA 2012;307:1433-5. 